\title{
CAVES IN SPACE
}

\author{
John Mylroie
}

\section{Abstract}

The definition of a cave has centered on its accessibility to humans, an understandable, but arbitrary, approach. Caves without humanly accessible entrances are still caves. As we reach out to the moons and planets of our solar system, and eventually the stars, we need to evaluate caves as possible reservoirs of extraterrestrial life and as potential human habitats. If humanly passable caves are a subset of all caves, then caves can exist from the tiny, subatomic dimension up to and including the entire universe. They can form and exist for only milliseconds or for billions of years. What's more, they can form in almost any solid material, and perhaps even in liquids, and contain within them vacuum, gases, liquids or solids. Caves can be initially classified as natural and artificial. Natural caves form either by constructive processes that build a boundary, which contains the void, or by destructional processes that remove or shift material to create a void, where none existed before. Caves are defined by answering five questions: 1 . How did the void form? 2. How big is it? 3. How long has it lasted? 4. What does it contain? 5. How does it connect to exterior space? As humans move from a geocentric view of natural features to a more universal view, we need to see caves across a broader continuum of possibilities.

\section{Introduction}

At the National Speleological Society annual convention, on July 18-22, 2016, in Ely, Nevada, Dr. Penny Boston, who had recently been appointed Director of the NASA Exobiology Institute, convened a special session, entitled The Future of Cave and Karst Science and Exploration. The session had four presentations by: George Veni; John Mylroie and Joan Mylroie; Michael Spilde, Jason Kimble and Diana Northup; and Penny Boston. Dr. Boston's presentation was titled "Extraterrestrial Caves: Advanced Technologies in the Search" (Boston, 2016). After the four presentations were completed, there was a panel discussion composed of the four presenters with the audience. This discussion eventually began to contemplate how to view caves from an extraterrestrial perspective. One big question, from NASA's viewpoint, was what was a cave, and, perhaps more importantly, would extraterrestrial caves be the refugium for life on other moons and planets? The interactions between the panel and the audience were wide-ranging and, at times, innovative. Also, they were possibly controversial, as when George Veni suggested that the largest cave in the solar system was the underground ocean on Europa, a moon of Jupiter. Then, this author countered that the largest cave was the liquid outer core of the Earth, both being subsurface, fluid-filled chambers. An important point made by Penny Boston was how to present caves to other NASA scientists and administrators. As many cavers and cave scientists have long known, people not associated with caves commonly do not understand them, and have many misconceptions about caves in general. How do we, as cavers and cave scientists, present caves to NASA? Discussions continued informally after the session ended.

After the convention, this author began to contemplate the problem of defining caves from a solar system or, perchance, an entire universe perspective. After some initial ideas were placed on paper, the author eventually prepared a PowerPoint presentation. At the 17 $7^{\text {th }}$ International Congress of Speleology in Penrith, Australia on July 25, 2017 (almost a year to the day from the NSS session in 2016), the author gave the presentation in the Extraterrestrial Caves session (Meredith and Moore, 2017). Ironically, the presentation was a substitute for a talk originally submitted by Drs. Penny Boston and Diana Northrup, cancelled because Penny Boston could not attend. The presentation generated a great deal of spirited discussion, and it was proposed that the ideas presented should end up in the cave and karst literature. Hence the origin of this paper.

To make a clean break from an Earth-centered and human bias, it was decided to start from an especially simple and basic first principles approach. To avoid preconceptions, this discussion will depart from many of the standard terms used by cavers and cave scientists, and address a few important themes. The first is, obviously, what is a cave? From that beginning, further questions center on the nature of the void, essentially, what is inside the void-vacuum, a gas, a fluid? What are the spatial and temporal aspects of a void, the sense of scale in time and space? Finally, how would we define such voids, or arrange them in a hierarchy? The author, as a life-long science fiction reader, has encountered numerous examples of fictional extraterrestrial caves, where the story characters are called spelunkers more often than not. The book, Caves of Karst (Hoffman, 1969), is a good example of science fiction and caving not mixing well. These stories helped document how unrealistically caves are viewed by non-cavers, while at the same time provided novel insights into other ways of thinking about caves (e.g., Wikipedia, 2018). It is time, as cavers, to step back and view caves from an extraterrestrial viewpoint with new eyes. 


\section{What is a Cave?}

The definition of a cave by cave scientists has almost always centered on the ability of humans to enter and explore an underground void, as presented by White (1988), Klimchouk (2004), Neuendorf et al. (2005), White and Culver (2005), Ford and Williams (2007), and Palmer (2007), among others. Portions of caves too small to admit humans are not caves according to Davies (1960). The single best treatment of what defines a cave is the classic article by Rane Curl (1964), "On the Definition of a Cave." Rane Curl recognized, as had many authors, the relative arbitrariness of using human beings as the dimensional frame of reference, perhaps best illustrated by Figure 1. A cave that humans can fit into was labeled by Curl (1964, p. 2) as a "proper cave," stating that such caves were a subset "of all subterranean cavities," in contrast to the limitations set by Davies (1960). Most importantly, he noted that, "A cave is a space rather than an object and consequently its definition involves the specification of its boundaries." (Curl, 1964, p. 1). Howard (1960) argued, "An opening is any volume surrounded by solid rock, but not filled by solid rock ... (it) may be filled with air, water, loose rock, mineral, clay or other debris ...." Use of humans to define caves will not work as we move into outer space, and possibly find life in underground voids.

Many of the authors above also wrestle with whether or not a cave must have a humanly accessible opening to the outside. It would seem ludicrous to characterize an underground void as not a cave because humans could not enter

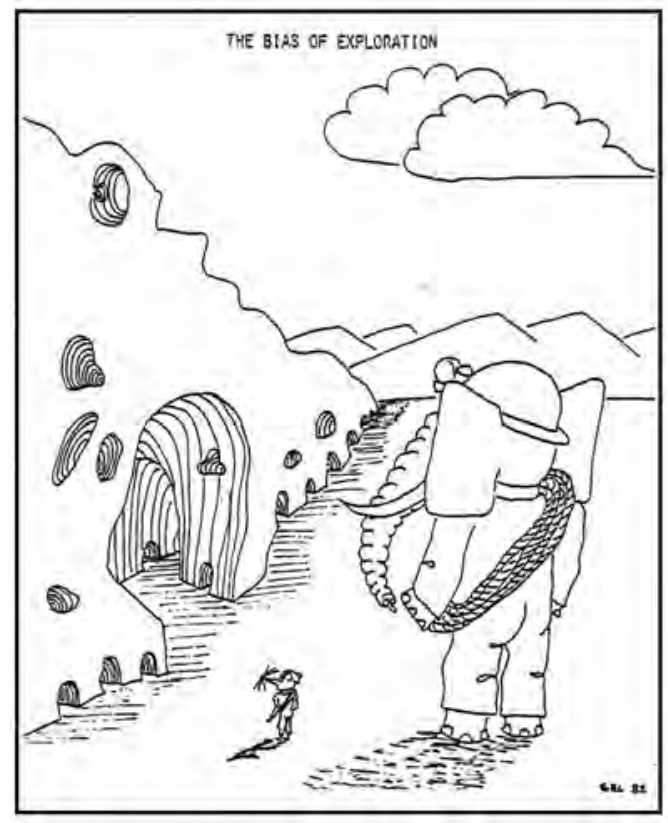

Figure 1. The Bias of Exploration, a cartoon by Dr. Stein-Erik Lauritzen, a Norwegian cave scientist, displays the problems when using an organism as the frame of reference for defining a cave. From Lauritzen (1983). or solids from water ice to hydrocarbons. If a pre-existing cave is infilled completely by another solid material, be it ice or clay, as occurs on the Earth, is it still a cave? It was certainly a cave at one time. As demonstrated by Figure 4, cave

Figure 2. Caves as "interior space:" A) The interior space is isolated from the exterior space. B) The interior space has a connection to the exterior space, allowing direct exploration. Topologically, the interior space is now an extension of the exterior space. it. Is a cave, suddenly opened by a quarry, not a cave prior to the blast that opens it? If we ignore, for the moment, the human-sized issue, a cave can be defined as an interior space isolated from an exterior space (Fig. 2A). If an entrance connects the interior space to an exterior space, even if that connection is small, relative to the size of the interior space, the interior space is, topologically, just an extension of the exterior space (Fig. 2B). Again, Curl (1964) explored this matter, defining a cave entrance as "...another form of boundary to the cave space." It is conceivable that a cave, such as a lava bubble, could have life evolve inside it, from purely inorganic material, utilizing chemosynthesis for an energy source, without the void ever having had any connection to the outside space. Earlier, Curl (1958) had investigated the statistics of cave entrances, predicting that a large number of entrance-less caves existed. Varnedoe (1973) and White,(1988) demonstrated that thousands of entrance-less caves existed in Alabama, and were actually the most abundant cave type (Fig. 3).

\section{What is in and Around the Cave?}

A key question is what is in the cave? Howard (1960) stated that a cave could contain air, water, or various sediments. A lava tube on the Moon would contain a vacuum. Is a lava tube still full of magma a cave? If a cave can be filled with water and visited by cave divers, a lava tube, filled with molten rock, must also still be a cave, although exploration with current technology would be a problem (Fig. 4). On other bodies in the solar system or elsewhere in the universe, the cave could contain a variety of gases from hydrogen to chlorine, fluids from liquid methane to liquid mercury,

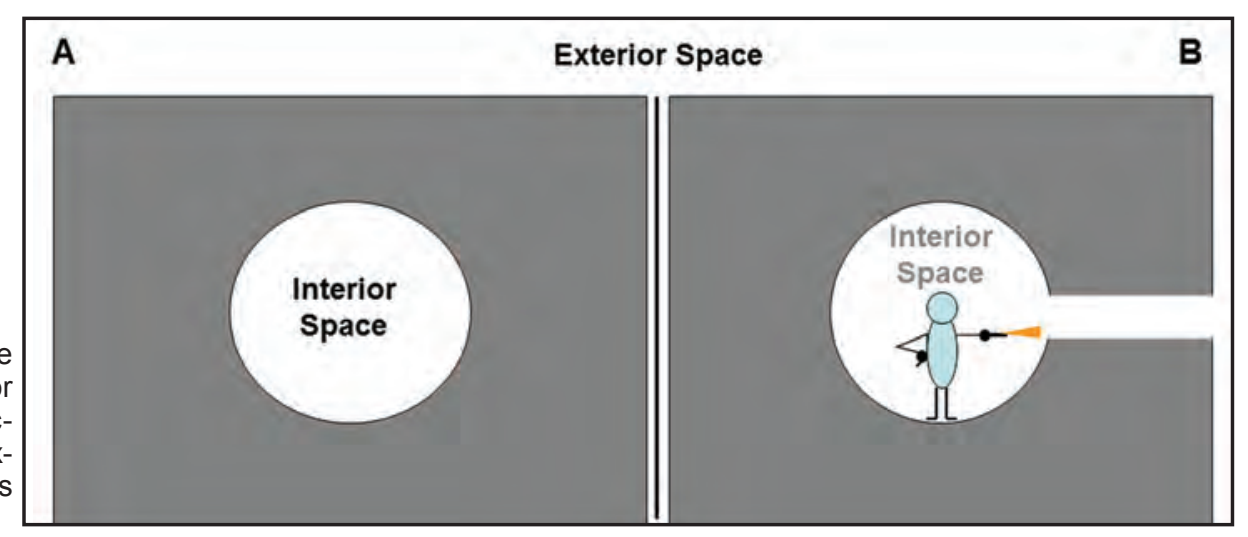




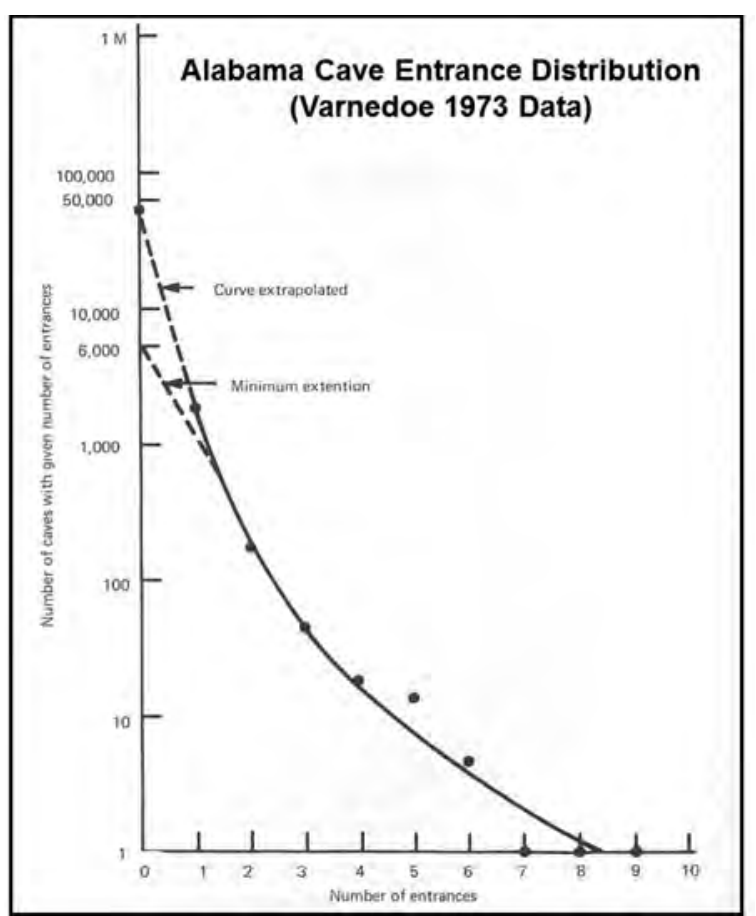

Figure 3. Plot of cave entrance number versus cave abundance data for Alabama (1973 data). The plot shows that the entrance number is inversely proportional to the number of caves, and that extending the plot to zero entrances demonstrates a minimum of 6,000 entrance-less caves, with perhaps as many as almost 50,000 . The plot assumes the proper caves of Curl (1964). From White (1988).
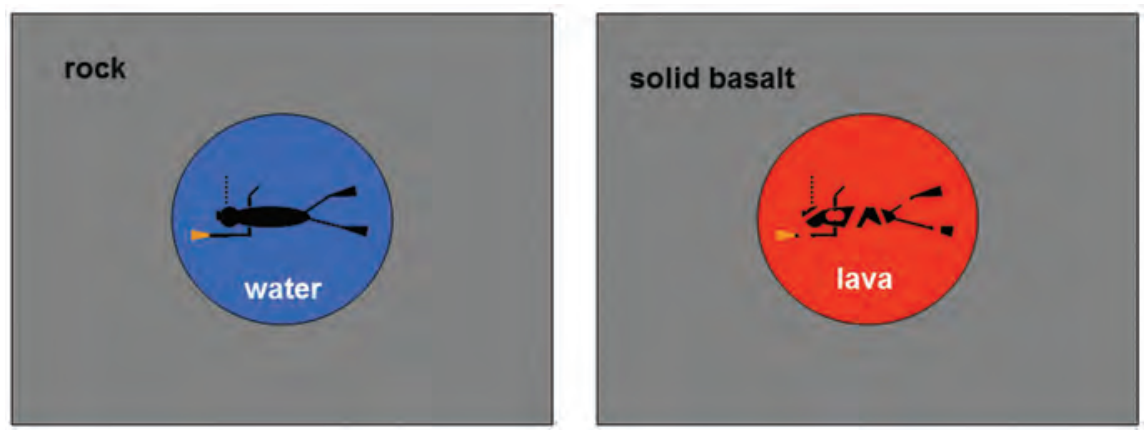

Figure 4. Examples of fluid-filled caves: A) Water-filled, a common type of cave subject to exploration with current technology. B) Lava-filled, also common, but not subject to exploration with current technology (at least, not for long). "empty space" does not mean a vacuum. The void as a concept should be considered non-dimensional. Underground voids are sought by geophysicists, who specifically name them "subsurface voids" (e.g., Keary et al., 2002, Burger et al., 2006). Those voids do not contain a vacuum or simply air; they may also contain water, sediment or other deposits. These voids are detectable by geophysical techniques, precisely because the void is different in physical character from its surrounding material. For this discussion, a void is a region different from that which surrounds it.

\section{Spatial and Temporal Aspects of a Cave}

If we accept for the moment that a cave is a void with boundaries, then we are faced with two questions. What is the possible size range of the void, and what is the duration of the void's existence? How small can a void be, and how large? From a purely theoretical point of view, the smallest measured objects in the universe are the building blocks of subatomic particles, quarks, at $\sim 0.43 \times 10^{-16} \mathrm{~cm}$ (ZEUS Collaboration, 2016). Depending on how the quarks were arranged to form a void boundary, the "cave," so enclosed, could be smaller than the quarks themselves, or exceedingly small. Considering such a tiny void as a cave is a bit far-fetched, but viruses can be as small as 100 nanometers (Harris, 
2006), so life, both on Earth and elsewhere, can be in exceptionally tiny voids. The other extreme measure of size would be the entire universe, which has a radius of 92 billion light-years (Redd, 2017). As nothing is known to exist beyond that scale dimension, the universe acts as a boundary to all it encloses, in the sense of Curl (1964), and we are all in an enormously big cave. On the Earth, cave size is determined by the structural nature of the enclosing material (usually rock) and the stresses that are placed on that rock, as explained by White (1988) in his discussion of the processes of cave breakdown. A cave on Earth can only be so big before the cave boundary (roof) fails. Not only are the materials in extraterrestrial conditions likely to be different than rocks in the Earth, the stresses under which those materials exist will also be very different than on Earth: gravity, rotational forces, temperature regime (including fluctuations and the timing of those fluctuations), photochemical and radiation effects, shock waves from impacts and in situ quakes, and tidal stresses. Lava tubes on the Moon are reported to be far bigger than any known on the Earth (Kaku et al., 2017), most likely as a result of the lower gravitational stresses. Otherwise, the Moon is a very Earth-like body in terms of composition, solar loading (albeit on a different time scale given the lunar day), and orbital characteristics. Lunar lava tubes indicate that the lack of an atmosphere is no impediment to cave formation. Moons like lo, which have erupting sulfur volcanoes, indicating a tube delivery system (caves) in the subsurface, are heated by tidal forces not experienced on Earth, to create a speleogenetic environment. In this case, the stresses help to make the cave, not destroy it.

Cave size has been the single most important characteristic of a cave for cavers on Earth. We want to know how big the cave is, both in terms of length, and in terms of passage size. Terms like "walking passage," "stoop-walk," and "crawlway" carry information on cave size, as does "dome," "pit" and "hand-climb" in terms of vertical dimensions. Cave size depends on the specific conditions in existence at the time of cave formation, and on the history of the cave since its genesis. Furthermore, cave size will be relevant in extraterrestrial situations, only as it relates to the purpose of the mission at the time and the technology available. Missions to outer space with humans aboard are less likely than robotic missions, as the recent Mars rover work has demonstrated (Mann, 2012). The efforts of people like Bill Stone to develop technology to penetrate underground oceans on Europa are a similar robotic application. Recent work to develop probes that can penetrate the rubble of collapsed buildings for rescue purposes (e.g., Guizzo, 2011) have utilized robots of less than human size. If we are looking for life on other planets and moons, then we must be prepared to look for caves of all sizes. As well, if we are merely looking for a cave habitat that we can exist in, then the human dimension (proper caves) again becomes important, and the existence of large lava tubes on the Moon and Mars will become a focus of attention.

The dimension of size is not the only question. We are also interested in the dimension of time. When did the cave form, and how long will it last? Age and duration are, therefore, important. As with spatial dimensions, chronological dimensions also have extreme end members. How long must a cave exist to be thought a cave? Consider a bullet fired into water (Fig. 5A), the passage of the bullet into the fluid creates a void that exists for milliseconds to seconds of time. Is this void a cave? On Earth, we have caves that can form and disappear within human memory, such as caves in glacial ice, or caves in salt (Figs. 5B and C). Both ice and halite are rheids, deformable solids. Compared to caves that are millions of years old, such as Mammoth Cave, Kentucky (Palmer, 2007), ice and salt caves exist, but form and disappear in a blink of geologic time. In high altitude and high latitude regions of the earth, caves form in snow each year, and disappear each summer. If a snow cave forms and disappears in the same place each year, is it the same cave every time? Then, if a bear hibernates in it every year, is the bear in a cave? Do voids form in the frozen $\mathrm{CO}_{2}$ polar caps on Mars; could they harbor life in frozen suspension? We keep track of many short duration events. The transuranium elements commonly have half-lives measured in seconds to milliseconds; they are formed in the laboratory. Thus, they exist and then they are gone. Transient as they are, we document them precisely. As presented earlier, if bubbles in water are caves, then they form and perhaps disappear in greater numbers and in shorter time spans than any other cave type on Earth. Bubbles in lava can be larger and exist far longer; being a bubble does not mean any obligatory size or temporal persistence. Caves are transient features; how transient depends on the scale of interest to the observer. How long can caves exist? Some of the oldest caves on Earth are in Australia, with ages going back more than 300 million years (Osborne, 2014). Lava tubes on the Moon may well be billions of

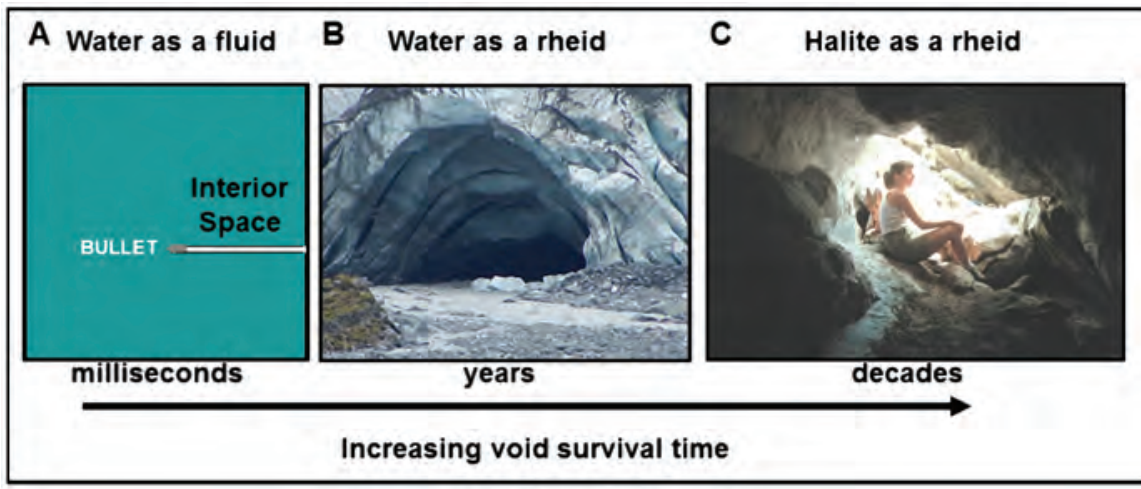

Figure 5. Examples of cave duration much shorter than average: A) A bullet fired into water creates a void that lasts milliseconds to seconds. B) Water ice is a rheid, a deformable solid, and ice caves can squeeze shut in a matter of years. C) Halite is also a rheid, and caves can squeeze shut in a matter of decades. 
years old (Kaku, et al., 2017). On the scale of most major geologic processes, such as plate tectonics and evolution, caves can span the duration of those events. Planets and moons evolve through time. Some not very much, such as the Earth's moon, which displays landforms that appeared billions of years ago. Others, such as lo, are actively resurfacing. Mars in particular has undergone an aging process that resulted in cooling of the planetary interior, with loss of much of its original magnetic field and loss of much of its atmosphere. While life may not be able to exist on the surface of Mars today, it may have in the past, and caves could be a refugium for some of those organisms. That action can only occur if the caves have survived for the long transition of Mars from its original state to the conditions of today.

\section{Cave Classification}

Almost every cave scientist has tried to come up with a classification of caves. For examples, see the authors associated with the definition of a cave in the Introduction section above. This author has also played with the topic (e.g. Mylroie, 1984; Mylroie and White, 1992), using, in the first case, solely caves in soluble rock, and in the second case, including pseudokarst caves. Classifying caves needs to be re-thought in terms of our extraterrestrial interests. Figure 6 is such an attempt. First of all, underground voids need to be separated into natural and artificial (e.g., Parise et al., 2013). Maybe the author has read too much science fiction, but we may encounter voids on planets or moons that were created by other life forms, either as burrows by non-sentient organisms, or as purposed structures built by sentient ones (e.g., Caves of Steel, Asimov, 1953; this book won the 1954 Hugo Award as best book of the year, a science fiction "Oscar"). News media commonly conflates artificial and natural caves (Parise, et al., 2013). Out in space, the scientist will need to discern clearly between the two. Natural voids form in two ways. Either the void was already there, and the boundaries were placed around it, a constructional cave (Mylroie and Mylroie, 2013; Gradziński et al., 2018; White

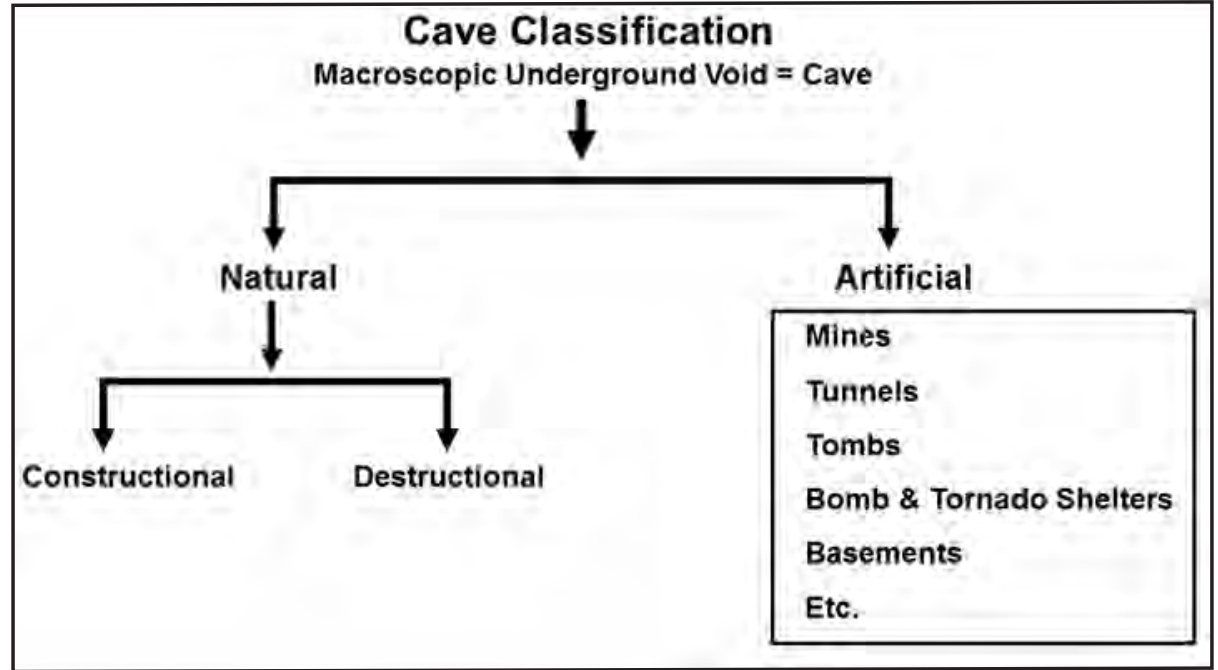

Figure 6. Simple classification of caves. In this case, a macroscopic underground void is assumed (the proper cave of Curl, 1964), such that human exploration is possible. Artificial caves smaller than humans exist, such as water pipes delivering water from the water main to a house. (See text for an explanation of constructional and destructional caves, or examine Figs. 8 and 9.)

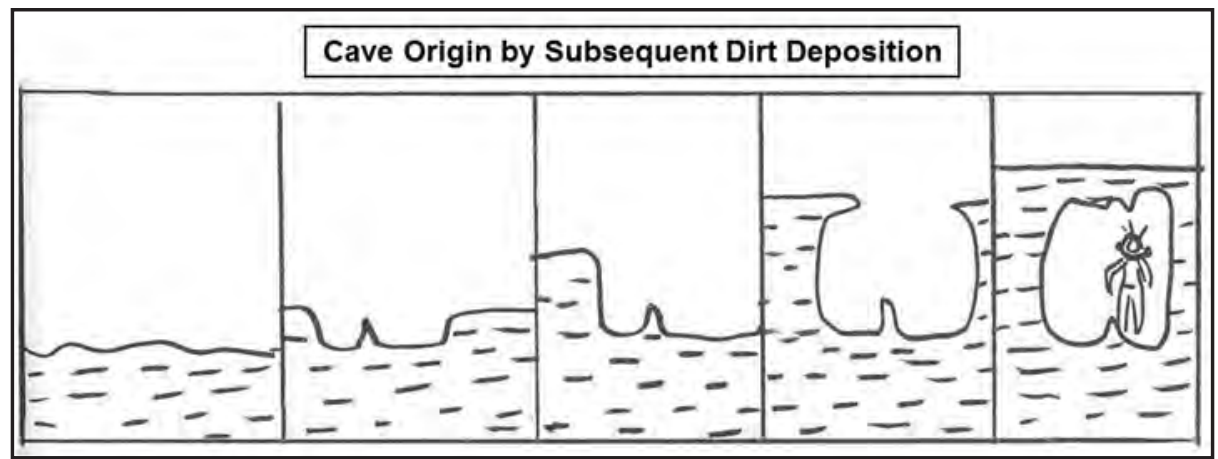

Figure 7. Cartoon of a caver's idea that a cave could be formed by building the void boundary around it, a constructional cave scenario. The cartoon was published prior to the Apollo Moon landings (Sweet, 1966). et al., 2018), as in a talus cave, or the boundary was already there and the void created within it; a destructional cave, as in a dissolutional cave. Figure 7 (Sweet, 1966) is a lighthearted approach to the constructional cave idea; note, it was published prior to the Apollo Moon landings. Figure 8 details the development of constructional caves in an idealized manner, subdividing the process into disordered or ordered (Figs. 8B and C, respectively). Destructional caves form by either moving the boundary material, as in fracture caves (Fig. 9A), or removing a material from within the boundary structure (Fig. 9B), by physical mass transport (e.g., suffosion caves), phase change (e.g., ice caves) or chemical processes (e.g., dissolutional caves). In all three cases, a pathway must be present to allow the material to exit to the exterior space, even if that pathway, as for dissolved material, is only a pore system millimeters in size. There are interesting extrapolations of this approach. If a gas evolves in a liquid, such as $\mathrm{CO}_{2}$ bubbles in a carbonated beverage, the original material (the soda) has been displaced, as opposed to being removed by the gas, to create the void, analogous to the boundary movement that makes fracture caves. Are bubbles, therefore, destructional caves? While ice caves form by a phase change from solid to 


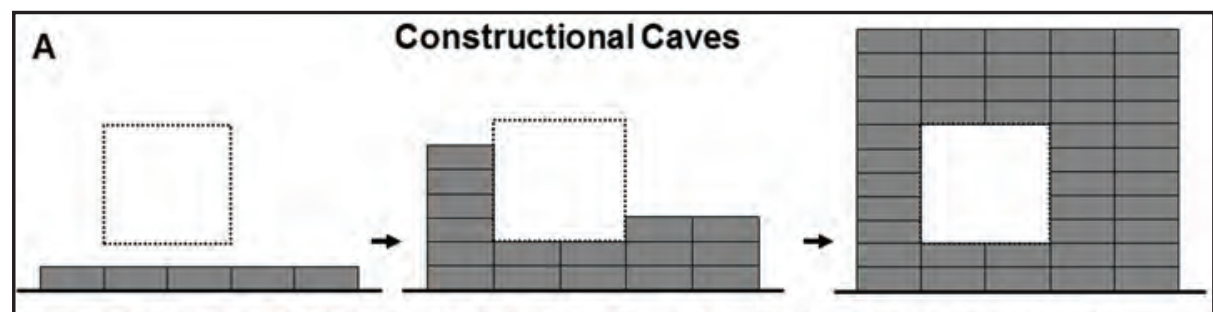

Cave created by adding material around a space that was already present

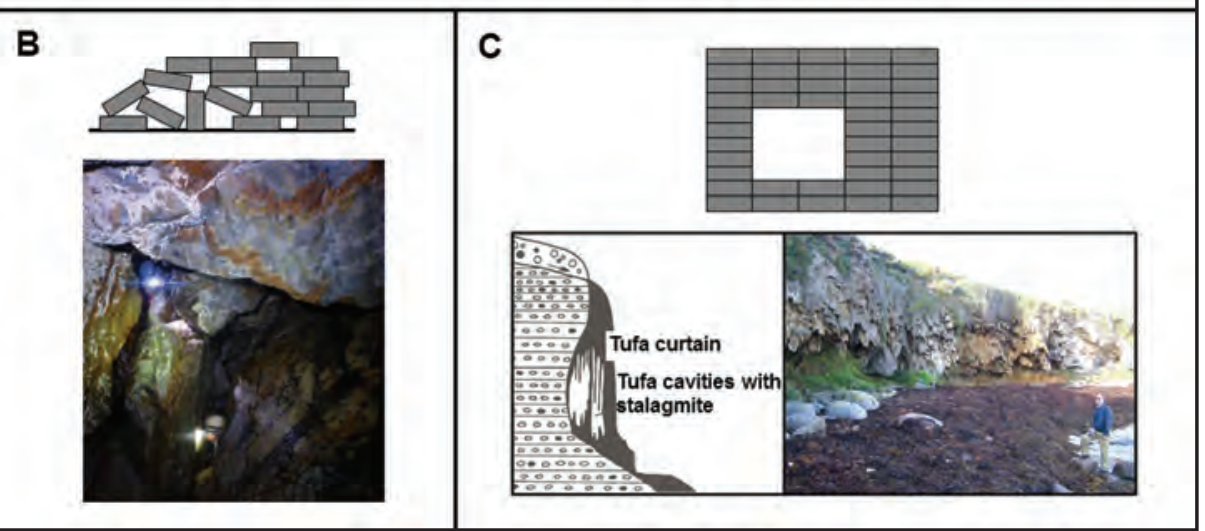

Figure 8. Constructional caves: A) Constructional caves form by building boundaries around a "pre-existing" void. In this diagram, the void is not symmetrically placed within the block to indicate that symmetry is not a requirement. B) An example of making a constructional cave by disordered application of the boundary, as in a talus cave (photo of Pittsford Cave, Vermont, courtesy of John Dunham). C) An example of making a constructional cave by ordered application of the boundary, as in a tufa cave. Diagram on the left was re-drawn from Bögli, 1980; photo on the right is a tufa curtain from the Margaret River coastal region, Western Australia. voids are made is a key step in determining the role those voids play in the landscape (or spacescape), and, perhaps if we are lucky, the local ecology.

\section{Is it a Cave?}

There are lots of arguments about what is a cave and what is not. Curl (1964) felt any underground void was a cave Destructional Caves

$$
\text { A }
$$

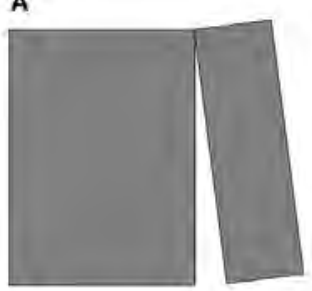

Fracture
B

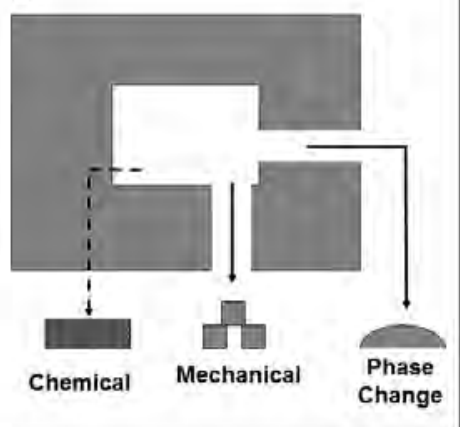

Figure 9. Destructional caves: A) Fracture of the boundary material, which requires movement or displacement to create the void (assuming we accept the Curl (1964) definition of a cave entrance as a boundary). B) Removal of boundary material by chemical mass transport, physical mass transport, or phase-change mass transport. Note that chemical diffusion of boundary material to the exterior space may utilize many especially small entrances. In both the $A$ and $B$ cases, the space that became the cave was not present prior to the destructional action. liquid, lava tubes form in the reverse, by solidifying the boundary, while the void remains in the fluid state, and then, mass transport evacuates the fluid. Technically, the molten lava does not have to depart, the void in that case is merely fluid filled. The departure of the fluid makes exploration by humans more feasible (e.g., Fig. 4). A tectonic fissure is an example of a destructional cave; but if breakdown blocks help to roof it over, then both destructional and constructional processes have helped to make the cave (Fig. 10). Figure 10 also demonstrates some of the bias among observers. Figure 10B would be considered a cave by most cavers, but Figure $10 \mathrm{~A}$ perhaps not, until at least the roofing stage had occurred, as seen in Figure 10C.

The point of offering this simple classification is to remind the observer that, while there are many processes that make caves, be it dissolution or pseudokarst, etc., there are only two ways to make a void: constructional and destructional. This approach makes it easier to assess voids found on other planets and moons. How in a continuum of void sizes, but if humans can enter, it was a proper cave. Davies (1960) felt that if humans could not enter, it was not a cave, hence, the dilemma of Figure 1. For extraterrestrial exploration, by human or robot, the "Curl Continuum" is best to use. We cannot pick and

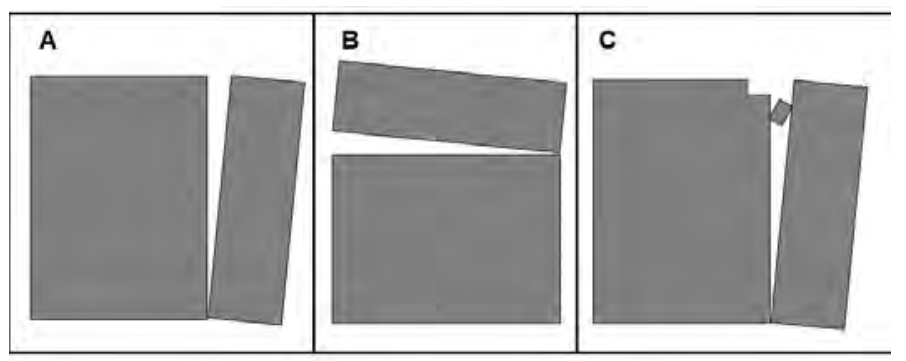

Figure 10. Three fracture cave situations: A) A vertically open fracture would be considered by many observers to lack a roof and, therefore, was not a cave. B) A $90^{\circ}$ change in orientation creates a roof, and many would now consider the fracture to be a cave; topologically $A$ and $B$ are the same. $C$ ) The fracture, a destructional cave, has had a roof added by a constructional process, talus generation. Most observers who considered A not a cave would consider $\mathrm{C}$ to be a cave. 
A
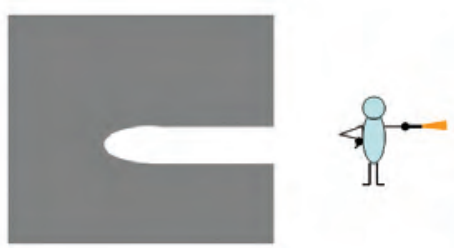

B

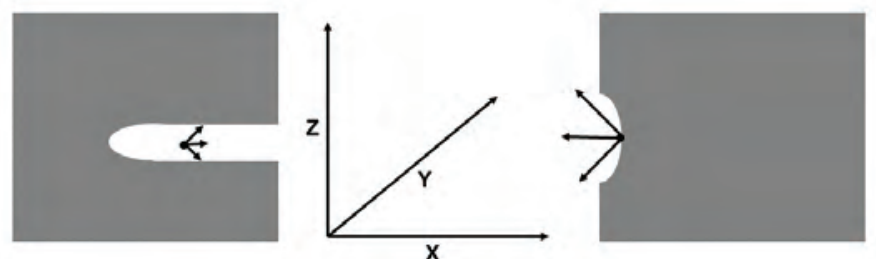

Figure 11. When is an indentation in a boundary material a cave? A) Two examples of indentations: The one on the left would be called a cave by most observers; the one on the right, is not a cave. Can this be qualified? B) Consider three axis that are mutually perpendicular. The shape of the right-hand indentation cannot keep any of the three vectors from directly reaching exterior space; however, the left-hand indentation cannot reach exterior space with any of the three vectors (the middle vector hits the cave wall between the vector and the viewer). decide, at any dimensional scale? Consider Figure 11B, with three vectors at right angles to each other. indentation is deep enough to accept the tri-axial figure, with its origin on the centerline of the cave, and block all three axes, then it is a cave; if not, then it is not a cave. For the special case of an indentation, that is circular with a radius of unity, the point at which the axes can no longer reach the surface is also unity. This means that any dimensional scale, be it nanometers, centimeters, meters or kilometers, will work if it is the unity radius of the indentation (Fig. 12). For other geometries, such as a wide slot, it may be sufficient to say only two vectors need to be blocked from exterior space. Figure 10 is an example where both $A$ and $B$ are caves by the tri-axial test, utilizing only two vectors. This treatment is presented just as an example to show that we can make decisions that, while arbitrary, are still based in geometry and not human dimension.

\section{Summary}

If we consider caves to be voids within a material, then whether the void is humanly enterable is a secondary condition; dimensional scale is not the issue. Dimensional scale is important to us, and it may also be important for life forms other than on Earth, but at dimensional conditions far different than what we expect. (That could be microbial life at the small scale, yet think of the large monster in the asteroid in the Star Wars movie, The Empire Strikes Back at the big scale). Chronological scale is a more difficult issue; how long must a void survive to be a cave? Technically, any time at all, from milliseconds to eons. However, voids with durations approaching human life spans are best for recreational caving. In the search for extraterrestrial life, the older the cave, the better. As in some cases, the cave may be the last refuge for life if the surface above has become inhospitable. If the cave itself has also become inhospitable, it may contain evidence of past life that has been erased from the surface above. Alternatively, if life currently exists in Europa's underground oceans, then the most recent water geysers and feeder pipes (caves) would be most likely to contain active life from below; very young caves could be important.

The question of extraterrestrial caves can be broken down into five subparts:

1. How did the void form?

2. How big is it?

3. How long has it lasted?

4. What does it contain?

5. How does it connect to exterior space?

If we can answer these five questions, we may be able to assess how that cave functions as a part of an extraterrestrial landscape, and how life may have utilized the cave in the past, or still utilizes it today. 


\section{Acknowledgements}

Many thanks to Penny Boston for getting this ball rolling, and to Diana Northup for arranging to have my PowerPoint be presented in the Extraterrestrial Caves session at the 17th ICS. The single reviewer and the editor improved the manuscript. Much gratitude to the many cavers and cave scientists who have shared ideas with me for almost five decades.

\section{References}

Asimov, I., 1953, Caves of Steel: New York, Pyramid Books, 189 p.

Bögli, A.,1980, Karst Hydrology and Physical Speleology: New York, Springer-Verlag, 284 p. https://doi.org/10.1007/978-3-642-67669-7.

Boston, P., 2016, Extraterrestrial caves: Advanced technologies in the search, 2016 National Speleological Society Convention Program Guide, Ely Nevada, Abstracts, p. 85.

Burger, H.R., Sheehan, A. F., Jones, C.H., 2006, Introduction to Applied Geophysics: New York, Norton, 600 p.

Cambridge Dictionary, https://dictionary.cambridge.org/us/dictionary/english/void.

Curl, R. L., 1958, A statistical theory of cave entrance evolution: Bulletin of National Speleological Society, v. 20, p. 9-22.

Curl, R. L., 1964, On the definition of a cave: Bulletin of National Speleological Society, v. 26, no. 1, p. 1-6.

Davies, W. E., 1960, Origin of caves in folded limestones: Bulletin of the National Speleological Society, v. 22, Part 1, p. 5-18.

Ford, D.C. and Williams, P., 2007, Karst Hydrology and Geomorphology: Chichester, Wiley, 562 p. https://doi.org/10.1002/9781118684986.

Gradziński, M., Bella, P., and Holŭbek, P., 2018, Constructional caves in freshwater limestone: A review of their origin, classification, significance and global occurrence: Earth-Science Reviews, v. 185, p. 179-201. https://doi.org/10.1016/j.earscirev.2018.05.018.

Guizzo, E., 2011, Japan earthquake: More robots to the rescue: IEEE Spectrum. https://spectrum.ieee.org/automaton/robotics/industrial-robots/ japan-earthquake-more-robots-to-the-rescue.

Harris, A. 2006, Influenza virus pleiomorphy characterized by cryoelectron tomography: Proceedings of the National Academy of Sciences, v. 103, p. 19123-19127. https://doi.org/10.1073/pnas.0607614103 [accessed December 20, 2017].

Hoffman, L., 1969, Caves of Karst: New York, Ballantine Publishing, 224 p.

Howard, A. D., 1960, Geology and origin of the crevice caves of the lowa, Illinois and Wisconsin lead-zinc district: Journal of the Yale Speleological Society, v. 2, n. 4, Part I, p. 63.

Kaku, T. Haruyama, J., Miyake, W., Kumamoto, A., Ishiyama, K., Nishibori, T., Yamamoto, K., Crites, S.T., Michikami, T., Yokota, Y., Sood, R., Melosh, H.J., Chappaz, L. and Howell, K.C., 2017, Detection of intact lava tubes at Marius Hills on the Moon by SELENE (Kaguya) Lunar Radar Sounder: Geophysical Research letters, v. 44, no 20, p. 10,155-10,161. https://doi.org/10.1002/2017GL074998.

Keary, P., Brooks, M., Hill, I., 2002, An Introduction to Geophysical Exploration: Oxford, Blackwell Science, 262 p.

Klimchouk, A., 2004, Caves, in Gunn, J., ed., Encyclopedia of Cave and Karst Science: New York, Fitzroy Dearborn, p. 203-205.

Lauritzen, S-E., 1983, Arctic and Alpine Karst Symposium: Oslo, Norway, University of Oslo, 89 p.

Mann, A., 2012, Humans vs. robots: Who should dominate space exploration? https://www.wired.com/2012/04/space-humans-vs-robots/.

Meredith, A-M and Moore, K., 2017, Conference Handbook, in Proceedings, $17^{\text {th }}$ of the International Congress of Speleology: Penrith, Au., Australian Speleological Federation, p. 110-111.

Mylroie, J. E., 1984, Hydrologic classification of karst landforms, in LaFleur, R., ed., Groundwater as a Geomorphic Agent: Boston, Allen and Unwin, p. 157-172.

Mylroie, J. E. and White, W. B., 1992, Cave Geology. in Rea, G. T., ed., Caving Basics: Huntsville, Ala, National Speleological Society, p. 123-139.

Mylroie, J.E. and Mylroie, J.R., 2013, Pseudokarst caves in the littoral environment, in Lace, M. J., and Mylroie, J. E., eds., Coastal Karst Landforms, Coastal Research Library 5: Dordrecht, Springer, p. 3-14.

Neuendorf, K.K.E., Mehl, J.P., and Jackson, J.A., 2005, Glossary of Geology, $5^{\text {th }}$ Edition: Alexandria, Va., American Geological Institute, p. 102.

Osborne, R.A.L., 2014, Understanding the origin and evolution of Jenolan caves: The next steps, in Proceedings of the Linnean Society of New South Wales: Kingsford, N.S.W., Au., v. 136, p. 77-97. https://www.biodiversitylibrary.org/item/206950\#page/80/mode/1up

Palmer, A.N., 2007, Cave Geology: Dayton, Ohio, Cave Books, 454 p.

Parise, M., Galeazzi, C., Bixio, R. and Dixon, M., 2013, Classification of artificial cavities: A first contribution by the UIS Commission, in Proceedings of the $16^{\text {th }}$ International Congress of Speleology: Czech Republic, Brno, v 2, p. 230-235. https://artificialcavities.files.wordpress. com/2013/09/contributo-brno2013_classification.pdf

Redd, N.T., 2017, How Big is the Universe? https://www.space.com/24073-how-big-is-the-universe.html.

Sweet, K, 1966, Cave origin by subsequent dirt deposition: MSM Spelunker, v. 10, no. 1, p. 17. in Plummer, W.T., ed., 1966 Speleodigest: Vienna, Va., National Speleological Society, section. 4, p. 5.

Varnedoe, W.W., 1973, Alabama Caves and Caverns: Huntsville, Ala., Privately published.

Vlahos, J., 2007, Robot subs in space, Popular Science, February 2007. https://www.popsci.com/military-aviation-space/article/2007-02/robotsubs-space. [accessed December 20, 2017]

White, W.B., 1988, Geomorphology and Hydrology of Limestone Terrains: New York, Oxford, 464 p.

White, W.B., and Culver, D.C., 2005, Cave, definition of in Culver, D.C. and White, W.B., eds., Encyclopedia of Caves: Burlington, Elsevier, p. 81-85.

White, S.Q., Grimes, K.G., Mylroie, J.E., and Mylroie, J.R., 2018, The earliest time of karst cave formation: Cave and Karst Science, v. 45, no.1, p. $15-18$.

Wikipedia, Subterranean Fiction. https://en.wikipedia.org/wiki/Subterranean_fiction.

ZEUS Collaboration, 2016, Limits on the effective quark radius from inclusive ep scattering at HERA: Physics Letters B, v. 757, p. 468-472. https://ac.els-cdn.com/S0370269316300776/1-s2.0-S0370269316300776-main.pdf? tid=4bc73369-159d-4be3-aacd-0a428bd8c153\&acdnat=1539695138_f0d6e06c2a9f00a3e1618989df75eb33 [accessed December 20, 2017] 